Jarkko Oraharju

\title{
Ei voi unohtaa, ellei muista. Muistitutkimuksen kysymykset ja Raija Siekkisen lyhytproosatekstit
}

\section{Muisti tuo esiin uutta}

Muisti on alkanut kuoriutua, kerros kerrokselta se tuo esiin uutta, siis vanhaa, niin kuin vanhaa taloa remontoitaessa löytyy kovalevylattian alta toinen lattia leveää lankkua, ja seinistä, kun levyt on poistettu, vanhojen tapettien repeilleitä, haalistuneita, pölyisiä kerroksia, katon yläpuolelta alkuperäinen katto: sen reunoja kiertävät raskaat, veistetyt profilitit. (Siekkinen 1999, 23-24.)

Raija Siekkisen (1953-2004) proosateksti pienoisromaanista Se tapahtui täällä (1999) käsittelee runollisesti omaelämäkerrallisen muistin aihetta. Siekkisen novelleista ja pienoisromaaneista voi tunnistaa kirjailijan hahmon ja hänen biografisia vaiheitaan, mutta tässä katsauksessa omaelämäkerrallisen muistin teema ei viittaa kerrottuun omaelämäkertaan vaan fiktiiviseen muistamisen kokemukseen. Siekkisen kertojat ja henkilöt muistavat elettyä elämäänsä. He pohtivat muistin olemusta ja merkityksiä. He kysyvät: miksi menneisyys palaa mieleen, miksi muistot asuttavat nykyisyyttä? Teksteissä tulee esille muistamisen prosesseja ja muistamisen tuottamia tulkintoja. Tekstit kertovat muistin vaikutuksista ihmisen kokemuksiin ja ruumiillisuuteen. Ne herättävät kysymyksiä: Miten henkilökohtainen muisti voidaan käsittää? Miltä oman elämän muistaminen tuntuu?

Muisti on aiheena laaja ja moniselitteinen. Muistia ja muistamista tutkitaan ja tulkitaan monitieteisesti erilaisista näkökulmista. Muistaminen on oleellinen ja myös arkinen ilmiö kognitiivisissa toiminnoissa. Samalla siihen liittyy myyttisyyttä ja tavoittamattomuutta. Mitä muisti tarkoittaa? Menneisyyden jatkuvuutta, oppimista, tapoja ja arvoja?

Muistia koskevat käsitykset alkoivat tarkentua 1800-luvun lopulla. Varhaiset muistin toiminnasta kiinnostuneet tutkijat, kuten Henri Bergson ja Sigmund Freud, tulivat filosofian ja psykologian piiristä. 1900-luvun alkupuolella muistikeskustelua vauhditti nykyisinkin käytetty Maurice Halbwachsin teoria kollektiivisesta muistista eli muistamisen yhteisöllisistä merkityksistä. (Erll 2008, 8-9.)

Nykyinen monitieteinen muistitutkimus (memory studies) pohjautuu 1980-luvulla tehtyihin lukuisiin muistia käsitteleviin tutkimuksiin, joiden näkökulmaa on nimitetty muistin käänteeksi ja muistibuumiksi. Uudessa muistitutkimuksessa on siirrytty sisällöstä rakenteisiin ja niihin tapoihin, joiden myötä muistetut asiat ylipäätään ovat olemassa. (Erll 2008, 1; Blight 2009, 240-243.) Muistitutkimus purkaa essentialis- 
mia ja kirjoittaa esiin muistamisen ongelmallisuutta: Kuka muistaa, kenen muisti on oikeassa, kenen muistot ovat poissa julkisuudesta?

Siekkisen "Vieras maa" -novellissa eräs henkilö ajattelee: "Ei voi unohtaa, ellei muista, sanoin itselleni. Yö yöltä katselin sitä, mitä oli ollut, ja se tyhjeni, loittoni, odotin että voisin sen niinkuin loppuun luetun kirjan panna hyllylle muiden joukkoon.” (Siekkinen 1991, 141.) Muistaminen näyttäytyy välttämättömänä, se vie lähemmäs elämisen ydintä, kohti henkilökohtaista totuutta. Pohdin, minkälaisia vastauksia edellä esitetyt muistitutkimuksen kysymykset saavat Siekkisen lyhytproosateksteistä.

\section{Kaunokirjallisuuden valaiseva lamppu muistitutkimuksessa}

Kaunokirjallisissa teksteissä katsotaan ajallisesti sekä menneeseen että tulevaan. Usein tekstit kertovat, mitä tapahtui. Birgit Neumannin (2008, 333) mukaan muistilla ja kaunokirjallisuudella on lukuisia yhtymäkohtia. Jo antiikin mytologiassa esiintyi muistin jumalatar Mnemosyne (Mustakallio 1996, 67-68). Muistaminen liittyy myös kirjallisiin genreihin, kuten muistelmiin ja autofiktioon. Mitä uutta muistitutkimus on tuonut kaunokirjallisuuden tulkintaan?

Kaunokirjallisuus yleistyi muistitutkimuksen aineistona 2000-luvulla (Erll 2005, 265; Foust Vinson 2010, 1). Kaunokirjallisuuteen sisältyvä menneisyyden rakentaminen ja rakentuminen sopivat muistitutkimukseen alaan, jossa ei olla niinkään kiinnostuneita muistojen sisällöstä vaan niiden merkityksestä osana nykykulttuuria. Muistojen 'nykyisyys' on keskeistä. Muistoissa mennyt on aina rakennettu jostakin näkökulmasta käsin. Kaunokirjallisuudessa tämä rakentumisen prosessi on konkretisoitunut luettavaksi. Astrid Erll (2011, 144-145) tulkitsee kaunokirjallisuutta nimenomaisesti kulttuurisen muistin mediana.

Kaunokirjallisuutta käytetään muistitutkimuksessa useista näkökulmista käsin. Kirjallisuus itsessään on usein muistamista, ja intertekstuaalisuus on tulkittu kirjallisuuden muistiksi siinä mielessä, että kirjallisuus muistuttaa kirjallisuudesta. Muistiteemallista tutkimusta on tehty myös lukijalähtöisesti, jolloin on käsitelty kirjallisuuden muistamista ja sen vaikutusta lukijatulkitsijoihin. (Skopljanac 2012, 198.)

Suzanne Nalbantian ja Evelyne Ender ovat käyttäneet 1800-luvun lopun ja 1900luvun alun kaunokirjallisuutta muistamisen psykologista ja kokemuksellista puolta selventävänä aineistona. He kuvailevat kaunokirjallisuutta muistitutkimuksen laboratoriona, jossa mielen toiminta valaistuu. (Nalbantian 2003, 1-3; Ender 2005 8-10.)

Saksassa kulttuurisen muistitutkimuksen alalla on tuotu esille muistitutkimuksen ja kaunokirjallisuuden yhteyttä kuvaavia käsitteitä. Birgit Neumann (2008, 334-336) käyttää termiä muistifiktio (fictions of memory), ja hänen käytössään käsitteellä on kaksoismerkitys. Yhtäältä muistifiktioita ovat kaunokirjalliset tekstit, jotka eivät viittaa mihinkään tiettyyn todelliseen tapahtumaan mutta jotka kuvaavat Siekkisen proosatekstien tapaan muistin toimintaa ja siihen liittyviä merkityksiä. Toisaalta muisti- 
fiktioihin liittyy myös selkeästi ei-fiktiivisiä elementtejä, kuten kulttuurisia käänteitä ja kansallisia traumoja. Kaunokirjallisuus vastaa lukijakunnan muistoihin.

Neumannin (2008, 337-338) mukaan metamuistin (metamemory) teema on yleinen nykykirjallisuudessa, jossa tutkitaan ja tulkitaan muistin toimintaa ja muistin totuudellisuuden problematiikkaa: näkökulmia, aukkoja ja tulkinnanvaraisuutta. Muistin mimesis (mimesis of memory) kuvaa muistin ja kirjallisuuden yhteyttä. Neumann kirjoittaa, että termi korostaa kaunokirjallisuuden keinoja tuottaa muistille merkityksiä. (Erll 2005, 265; Neumann 2008, 334.)

Lukuisissa muistitutkimuksellisissa teksteissä tulee esille Marcel Proustin kaunokirjallisten tekstien erityisyys muistitutkimuksen kannalta (Saarenheimo 2014, 49). Proustin muistisitaatit romaanisarjasta Kadonnutta aikaa etsimässä ovat käytössä myös psykologian ja käyttäytymistieteiden parissa määrittelemässä ja kuvaamassa muistin olemusta. Proustin yhteydessä on puhuttu muistin tahattomuudesta: mieleen nousee asioita, menneisyys ja sen merkityksellisyys paljastuvat kokijalle hitaasti. Proustin proosatekstit edesauttavat omaelämäkerrallisen muistin hahmottamista ja toimivat muistamisen kokemuksen kuvaamisen välineinä. (Greenberg 2015, 282-285.)

Muistitutkimuksessa on esitetty, että kaunokirjallisuus näyttäytyy oppaana, jonka avulla voi tulkita todellisuutta. Kirjallisuus opettaa muistin toimintaa ja sen merkitystä. Kaunokirjallinen muistamisen aihe saa meidät näkemään, miten muisti vaikuttaa meidän omaan elämäämme. (Erll 2011, 169-170; Foust Vinson 2010, 318.) Tässä mielessä kaunokirjallisuus on uudessa muistitutkimuksessa valaiseva lamppu, jonka avulla pystytään käsittelemään näitä muistamisen hämäriä alueita.

\section{Raija Siekkisen muistiproosa}

Miten Raija Siekkisen proosa sijoittuu kaunokirjallisuutta lähestyvälle muistitutkimuksen kentälle? Miten muistin mimesiksen voi käsittää hänen muistifiktioissaan?

Muistin ja muistamisen aiheita on huomioitu suomalaisessa kirjallisuudentutkimuksessa suhteellisen vähän (Rossi 2007, 8). Suomalaisen kirjallisuuden kontekstissa Siekkisen proosatekstien muistiaiheen käsittely ja laajuus on ainutaatuista. Vastaavaa tematiikkaa tulee esille Katja Seudun (2001, 23-31) tulkinnassa Antti Hyryn proosateksteistä.

Marja Saarenheimo $(2014,11)$ tuo esille kaunokirjallisuuden todistusvoiman muistikysymysten kannalta teoksessaan Muistamisen vimma: "Tieteellinen tutkimus on tuottanut valtavan määrän tietoa muistista, mutta se ei silti välttämättä tavoita muistamista subjektiivisena kokemuksena tai kaikkia muistamisen yksilöllisiä ja kulttuurisia merkityksiä. Kaunokirjallisuus taas askaroi usein juuri siellä, mihin tutkimus ei yllä.”

Siekkisen tekstien lukijana pystyn hahmottamaan tarkemmin mentaalisen muistamisen kokemuksen merkitystä. Siekkisen teksteissä muistin purkaminen näyttäytyy terapeuttisena ja eheyttävänä. Muisti on kerääntynyt meihin ihmisiin. Kaikille muis- 
toille ei ole vielä sanoja, mutta Siekkinen ohjaa teksteillään lukemaan muistamisen kokemusta. Siekkisen tekstit käsittelevät yksityistä muistamisen kokemusta, hiljaista tietoisuutta ihmisessä. Fiktiivisin keinoin kuvattu muistikokemus on juuri sellaista mihin tutkimus ei yllä, kuten laajalle levinnyt Proustin muistisitaattien käyttö todistaa. Siekkisen teksteissä rakentuva sisäinen ääni ja hienovarainen kokemuksen kertominen sijoittavat hänet Proustin jatkumolle muistamisen kirjoittajana. Katseen liikkeet, havainnot ja tulkinnat yhdistyvät. Merkitykset ja se, mitä tapahtui, ovat sanojen takana. Muisti elää ihmisessä:

Hän istui keinutuolissa ja antoi lampun valon kiertää ympäri huoneen: se tapahtui täällä. Hän näki suuren pöydän, penkin sen edessä, hetekan, ja tuvan toisessa päässä siron puukaluston: sohvan, tuolit, pöydän. Hän näki takan edustalla kaksi lattiatyynyä. Hän näki hetekan. (Siekkinen 1999, 57.)

\section{Kirjallisuus}

Blight, David W. 2009. The Memory Boom. Why and Why now? Pascal Boyer \& James V. Wersch (eds.), Memory in Mind and Culture. Cambridge: Cambridge University Press, 238-251.

Ender, Evelyne 2005. Architexts of Memory. Literature, Science and Autobiography. Ann Arbor: The University of Michigan Press.

Erll, Astrid 2008. Cultural Memory Studies: An introduction. Astrid Erll \& Ansgar Nünning (eds.), Cultural Memory Studies. An Interdisciplinary Handbook. Berlin: Walter de Gruyter, 1-15.

Erll, Astrid 2011. Memory in Culture. (Kollektives Gedächtnis und Erinnerungskulturen. Eine Einführung, 2005). Trans. Sara B. Young. London: Palgrave Macmillan.

Erll, Astrid \& Ansgar Nünning 2005. Where Literature and Memory Meet: Towards a Systematic Approach to the Concepts of Memory Used in Literary Studies. Herbert Grapes (ed.), REAL. Yearbook of Research in English and American Literature. Vol. 21. Literature, Literary History, and Cultural Memory. Göttingen: Gunter Narr Verlag Tübingen, 261-294.

Foust Vinson, Sarah Katherine 2010. Storied Memories: Memory as Resistance in Contemporary Women's Literature. Dissertations. Paper 176. Loyola University Chicago. http://ecommons.luc.edu/luc_diss/176 (1.12.2015).

Greenberg, Daniel L., Laurel L. Deasy \& Amelia L. Zasadski 2015. Autobiographical Memory. James D. Wright (ed.), International Encyclopedia of the Social \& Behavioral Sciences, 2nd edition, Volume2. Elsevier, 282-288. http://www.sciencedirect.com/science/article/pii/B978008097086851023X (1.12.2015). 
Mustakallio, Katariina 1996. Mnemosyne ja muistin synty antiikin maailmassa. Kirsti Määttänen \& Tuomas Nevanlinna (toim.), Muistikirja. Jälkien jäljillä. Tutkijaliiton julkaisusarja 80. Helsinki: Kirjapaino Oy Like, 66-74.

Nalbantian, Suzanne 2003. Memory in Literature: from Rousseau to Neuroscience. Hampshire \& New York: Palgrave Macmillan.

Neumann, Birgit 2008. The Literary Representation of Memory. Astrid Erll, \& Ansgar Nünning (eds.), Cultural Memory Studies. An Interdisciplinary Handbook. Berlin: Walter de Gruyter, 333-343.

Rossi, Riikka \& Katja Seutu 2007. Nostalgian lukijalle. Riikka Rossi \& Katja Seutu (toim.), Nostalgia. Kirjoituksia kaipuusta, ikävästä ja muistista. Helsinki: SKS, $7-12$.

Saarenheimo Marja 2012. Muistamisen vimma. Kirjoituksia muistista ja unohtamisesta. Tampere: Vastapaino.

Seutu, Katja 2001. Ja mieli on jakautunut maan yli. Muisti ja oleminen Antti Hyryn teoksissa. Helsinki: Otava.

Siekkinen, Raija 1991. Vieras maa. Kuinka rakkaus syntyy. Novellikokoelma. Helsinki: Otava.

Siekkinen, Raija 1999. Se tapahtui täällä. Pienoisromaani. Helsinki: Otava.

Skopljanac, Lovro 2012. Literature Through Recall. Ways of Connecting Literary Studies and Memory Studies. Interdisciplinary Literary Studies. Vol. 14. Nro: 2 2012, 197-212. 